monkeys' solution of PAN ambiguous-cue problems. Learning \& Motivation, 1972, 3, 334-340.

Fletcher, H. J., Grogg, T. M., \& Garske, J. P. Ambiguous-cue problem performance of children, retardates, and monkeys. Journal of Comparative \& Physiological Psychology, 1968, 66, 477-482.

Leary, R. W. The learning of ambiguous-cue problems by monkeys. American Journal of Psychology, 1958, 71, 718-724.

Medin, D. L. Role of reinforcement in discrimination learning set in monkeys. Psychological Bulletin, 1972, 77, 305-318.

Thompson, $\mathbf{R}$. Approach versus avoidance in an ambiguous-cue discrimination problem in chimpanzees. Journal of Comparative \& Physiological Psychology, 1954, 47, 133-135.
Zeaman D. \& House, B. J. Approach and avoidance in discrimination learning of retardates. Child Development, 1962, 33, 355-372.

\section{NOTE}

1. Boyer \& Polidora (1972) provide an empirical clarification regarding the apparently contradictory finding of superior performance as reported by Thompson (1954) and by Fletcher \& Bordow (1965).

(Received for publication November 15, 1972.)

\title{
A methodological critique of research on "superstitious" behavior
}

\author{
HANK DAVIS \\ University of Guelph, Guelph, Ont., Canada \\ JAMES HUBBARD \\ University of Tennessee, Knoxville, Tenn.
}

and

DOUGLAS REBERG

University of Western Ontario, London, Ont., Canada

Much recent research on superstitious behavior involves a procedure in which an instrumental response is pretrained and its rate of occurrence later recorded during a schedule of nonresponse-contingent reinforcement. It is argued that because this procedure fails to take into account the variety of alternative behaviors which might simultaneously be maintained by adventitious reinforcement, the data derived from such research cannot provide best evidence, whether positive or negative, for the general notion of superstitious behavior. The direct observational procedure originally employed by Skinner (1948) is proposed as being necessary for a more sensitive analysis of superstitious behavior.

In 1948, Skinner demonstrated that pigeons given regular deliveries of food emitted stereotyped patterns of behavior prior to each food delivery despite the fact that food was in no way contingent upon these repeated behaviors. This phenomenon, which is now referred to as "superstitious" behavior, is presumed to result from adventitious reinforcement or chance pairings between the "superstitious" operant and food delivery. " For some reason, since the publication of Skinner's 1948 paper, most research on superstition has replaced Skinner's direct observation technique with an analysis of superstition in which the data are obtained by measuring the rate of a single pretrained behavior, such as barpressing or keypecking, during a schedule of response-independent reinforcement (e.g., Neuringer, 1970). This approach is in keeping with the operant experimental tradition of automated data collection and is typified in the statement by Zeiler that the effects of "response independent reinforcement [are] studied more easily if the response is known, rather than if the experimenter must wait for some behavior to emerge through adventitious reinforcement [1968, p. 408].'

It is the purpose of the present paper to argue against the analysis of superstition in terms of the rate of a single behavior, and in favor of the direct observational method originally employed by Skinner (1948). The argument, stated simply, is that during nonresponse-contingent food delivery one cannot be sure which behaviors will be affected by contiguity with food; therefore, to record the occurrence of only one behavior reduces the sensitivity of the analysis and calls the conclusions into question. In making this argument, the conclusions of a particular paper will be the focal point of our criticism, not because the methods 

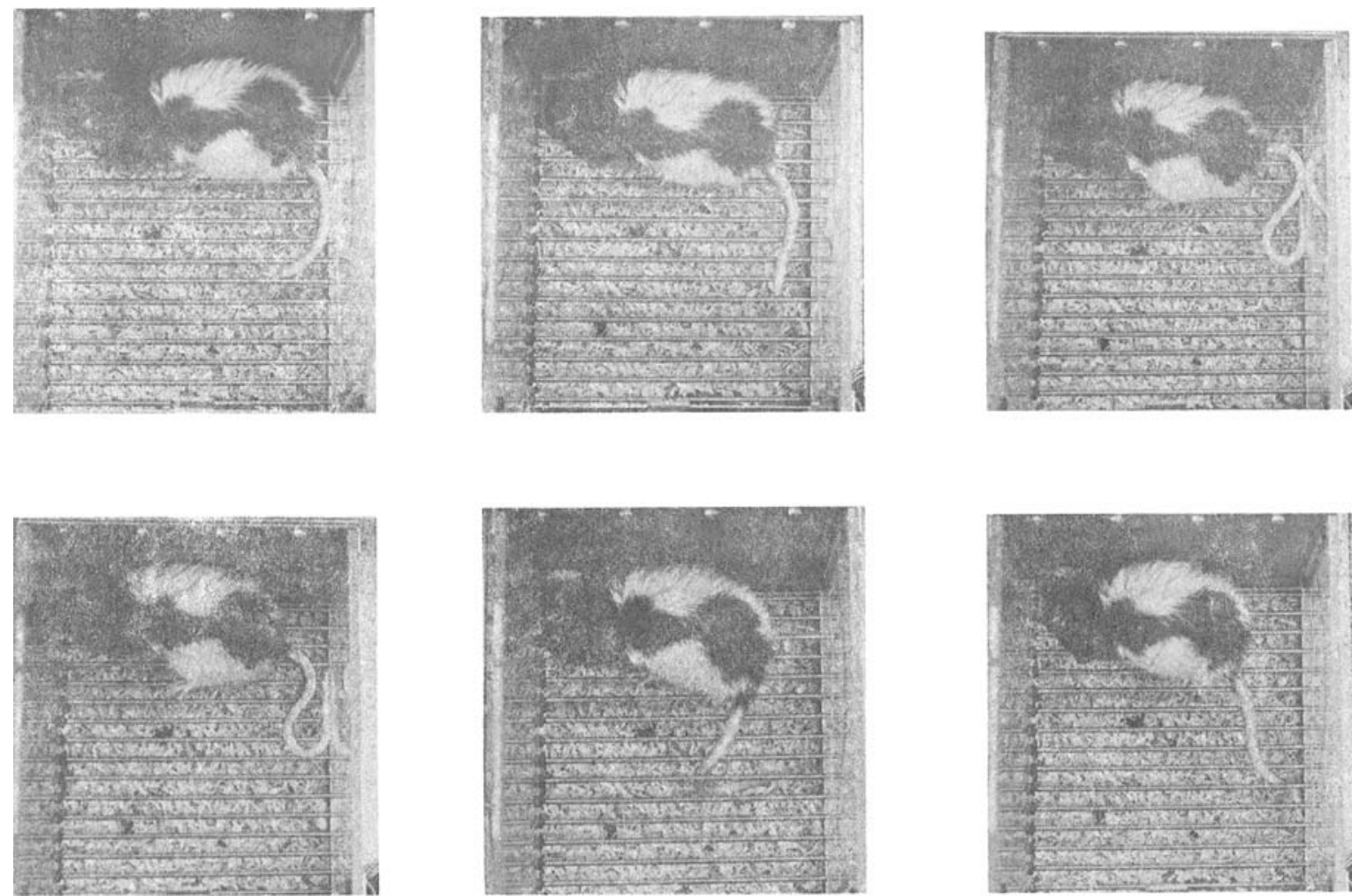

Fig. 1. Photographic record of $S$ exposed to fixed interval 30-sec schedule of nonresponse-contingent food delivery. Note similar orientation of S's body and right front paw while S "nosed" food tray (left front wall). This repeated behavior pattern resulted in several "accidental" contacts with the bar (middle front wall) and a spurious barpress count, which might have been misinterpreted had the $S$ been pretrained to barpress and not observed during measurement of superstition.

employed in this research were any different or worse than those of other superstition studies, but rather because the evidence derived from this procedure was used against the role of adventitious reinforcement. It should be noted at the outset, however, that in criticizing the pretraining and measurement of a single response technique, we are also calling into question, albeit ironically, a wealth of evidence typically used in support of superstitious behavior.

Rescorla \& Skucy (1969) have proposed an analysis which dismisses the role of adventitious reinforcement in maintaining the residual barpressing recorded in their study. In view of what Rescorla has previously had to say about the importance of a contingency, rather than temporal contiguity, in establishing and maintaining learned behavior (e.g., Rescorla, 1967), it is not surprising to find this argument against food as a nonresponse-contingent reinforcer. In fact, it is doubtful whether the term "noncontingent (i.e., adventitious) reinforcer" can exist under Rescorla's (1967) theoretical system.

Rescorla and Skucy suggest that the persistent barpress response is maintained either by what they term "learned" or "unlearned stimulus characteristics of the food." With regard first to "unlearned" factors, they argue that nonresponse-contingent food may maintain a barpress, or even evoke barpressing in naive animals, because "... food delivery presumably activates the animal, at least keeping it awake. Furthermore, the food magazine is near the bar; thus, animals kept near the magazine are likely to have a higher barpress rate [1969, p. 387]." Unless this argument assumes that a food pellet can function as an unconditioned stimulus which elicits perfectly formed barpressing in rats, i.e., stereotyped in topography from trial to trial, then it would seem appropriate to substitute a direct observational procedure for the measurement of a single response. That is, because stereotypy is often cited as one of the essential characteristics of superstitious behavior (e.g., Herrnstein, 1966), it is essential to know whether the barpressing recorded by Rescorla \& Skucy (1969) retained an identifiably consistent topography. For example, recorded barpresses could also be the result of occasional contacts between the bar and the animal's body that occur as a by-product of unrelated behavior patterns. This information would be helpful in determining whether or not recorded barpressing was superstitious, or whether, as Rescorla and Skucy imply, "unconditioned stimulus characteristics of the food" have simply activated the animal into occasional contacts with the bar of sufficient force to operate the microswitch. Even if barpressing were "accidental," the 
behavior patterns upon which such sporadic barpressing is based may be nonetheless stereotyped and superstitious. In the absence of some form of observation, however, this remains unknown (see Fig. 1).

Rescorla and Skucy also argue that "learned stimulus characteristics of the food," rather than adventitious reinforcement, may maintain barpressing in the absence of a barpress-food contingency. Their position is basically that food takes on discriminative or cue properties by virtue of its previous association with barpressing. According to Rescorla and Skucy, such an experimental history would be sufficient for food to occasion continued barpressing even in the absence of a contingent relationship between the barpress and food. If this is true, it is unlikely that the criterion of stereotypy could be used to distinguish between barpressing maintained by adventitious reinforcement and barpressing occasioned by food as a discriminative stimulus. Both responses would be expected to maintain an element of stereotypy. Nevertheless, the direct observation procedure would again be relevent, since there are many behaviors other than barpressing which are available to the organism in the test apparatus. If observation reveals any such repeated pattern of responding during the delivery of nonresponse-contingent food, it is unlikely that the concept of "learned stimulus characteristics of the food" could be invoked to account for it. That is, without an experimental history of contingency between this other behavior and food, its presence in the experimental situation cannot readily be explained by reference to food as a discriminative stimulus.

Although the barpress data presented by Rescorla \& Skucy (1969) would tend to support an argument against adventitious reinforcement, one must exercise caution in generalizing the conclusions drawn specifically about barpressing to the broader class of superstitious behavior in general. In short, because of the variety of forms superstitious behavior can take, neither "learned" nor "unlearned stimulus characteristics of food" may supplant adventitious reinforcement as an explanatory concept in the absence of direct observational data. Consider a situation in which an animal pretrained to make a specific instrumental response has also been observed to thrash its head from side to side (e.g., Hodos, Ross, \& Brady, 1962) or nibble its tail repeatedly (e.g., Laties, Weiss, Clark, \& Reynolds, 1965). If these observations had not been made, the absence of barpressing or keypecking in either of these situations might have led to the false conclusion that no superstitious behavior occurred.

The hypothesis stressing unconditioned "stimulus characteristics of food" is not necessarily incompatible with an analysis in terms of adventitious reinforcement and superstition. Consider, for example, a recent study on superstitious behavior in which Skinner's 1948 nonpretraining procedure was extended from pigeons to rats and from fixed to variable interval schedules of food delivery (Davis \& Hubbard, 1972). Many of the observed behavior patterns in this experiment did center in the area of the food tray; however, the stereotypy of these behaviors makes it seem more likely that while they may originally have been directed to the tray because of general activation in that area, they were later maintained adventitiously through repeated contiguity with food delivery. In fact, several of these behavior patterns resulted in occasional body contacts with the bar (see Fig. 1) of the variety implied by Rescorla and Skucy's "unlearned characteristics" argument; however, the observational method employed in this study allowed us to note the stereotypy of these movements and make a reasonable inference regarding their nature.

In short, despite the obvious procedural convenience, it appears doubtful whether a pretraining procedure can be relevant to the analysis of superstitious bahavior unless it allows for the subsequent observation of all behavior occurring in the test cage which might have been adventitiously reinforced. A recent experiment reported by Staddon \& Simmelhag (1971) indicates that such observational techniques must in no way be incompatible with the obvious procedural advantages of automated data collection.

\section{REFERENCES}

Brown, P. L., \& Jenkins, H. M. Auto-shaping of the pigeon's key-peck. Journal of the Experimental Analysis of Behavior. 1968, 11, 1-8.

Davis, H., \& Hubbard, J. An analysis of superstitious behavior in the rat. Behaviour, 1972, 43, 1-12.

Herrnstein, R. J. Superstition: A corollary of the principles of operant conditioning. In W. $K$. Honig (Ed.), Operant behavior: Areas of research and applications. New York: Appleton-Century-Crofts, 1966.

Hodos, W., Ross, G. S., \& Brady, J. V. Complex response patterns during temporally spaced responding. Journal of the Experimental Analysis of Behavior, 1962, 5, 47 3-479.

Laties, V. C., Weiss, B., Clark, R. L., \& Reynolds, M. D. Overt "mediating" behavior during temporally spaced responding. Journal of the Experimental Analysis of Behavior, 1965, 8, 107-116.

Morse, W. H., \& Skinner, B. F. A second type of superstition in the pigeon. American Journal of Psychology, 1957, 70, 308-311.

Neuringer, A. J. Superstitious key pecking after three peck-produced reinforcements. Journal of the Experimental Analysis of Behavior, 1970, 13, 127-134.

Rescorla, R. A. Pavlovian conditioning and its proper control procedures. Psychological Review, 1967, 74, 71-80.

Rescorla, R. A., \& Skucy, J. C. Effect of response-independent reinforcers during extinction. Journal of Comparative \& Physiological Psychology, 1969, 67, 381-389.

Skinner, B. F. "Superstition" in the pigeon. Journal of Experimental Psychology, 1948, 38, 168-172.

Staddon, J. E. R., \& Simmelhag, V. The "superstition" experiment: A reexamination of its implications for the principles of adaptive behavior. Psychological Review, 1971, $78,3-43$.

Zeiler, $M$. D. Fixed and variable schedules of response-independent reinforcement. Journal of the Experimental Analysis of Behavior, 1968, 11, 405-414.

\section{NOTE}

1. Such superstition must be distinguished from at least two other uses of the term. Morse \& Skinner (1957) refer to "sensory superstition," under which a stimulus present when a response is reinforced acquires discriminative control over response rate by virtue of this adventitious pairing. Brown \& Jenkins (1968) refer to the "autoshaping" phenomenon as a third type of superstition procedure in that the delivery of reinforcement is contingent upon the presentation of a stimulus, irrespective of the response emitted.

(Received for publication April 13, 1973.) 